\title{
EFEITOS DA FALTA DE PLANEJAMENTO URBANO NA BACIA DO CÓRREGO LAGOINHA EM UBERLÂNDIA - MG
}

\author{
Flábio Gonçalves ${ }^{(a)}$, Ana Paula Vieira Marques ${ }^{(b)}$, Adria Rodrigues Fontes ${ }^{(c)}$, João Donizete \\ Lima $^{(d)}$

\begin{abstract}
${ }^{(a)}$ Programa de Pós-Graduação em Geografia. Universidade Federal de Goiás - UFG. Regional Catalão. Contato: flabiogon@ yahoo.com.br. Mestrando do Programa de Pós-Graduação em Geografia.

${ }^{(b)}$ Programa de Pós-Graduação em Geografia. Universidade Federal de Goiás - UFG. Regional Catalão. Contato: anapavim@gmail.com. Mestranda do Programa de Pós-Graduação em Geografia.

${ }^{(c)}$ Programa de Pós-Graduação em Geografia. Universidade Federal de Goiás - UFG. Regional Catalão. Contato: adria1969@gmail.com. Mestranda do Programa de Pós-Graduação em Geografia. donizeteufg@ gmail.com. Professor Doutor do Programa de Pós-Graduação em Geografia.
\end{abstract} \\ ${ }^{(d)}$ Programa de Pós-Graduação em Geografia. Universidade Federal do Goiás - UFG. Regional Catalão. Contato:
}

\section{EIXO: BACIAS HIDROGRÁFICAS E RECURSOS HÍDRICOS: ANÁLISE, PLANEJAMENTO E GESTÃO}

\begin{abstract}
Resumo
O artigo visa demonstrar que o Córrego Lagoinha em Uberlândia-MG não possui vazão suficiente para escoamento de chuvas e que contaminado devido ao esgoto clandestinos. O objetivo do trabalho foi constatar e demonstrar a existência irregular de esgoto, falta de vazão adeauda da água e contaminação por lixos. O resultado encontrado em relação às enchentes foi a falta de impermeabilização do solo na região do Córrego devido às várias contruções, asfalto e áreas concretadas e também por haver saída única de água que é insuficiente. Já em relação à contaminação e poluição da água dá-se pelos esgotos clandestinos e pelos lixos encontrados no leito da Baci. Enfim, o artigo teve como resultado uma pesquisa que demonstrou que o Córrego está com sérios problemas ambientais para serem resolvidos, como: retirada de lixo, retirada do esgoto clandestino, abertura de áreas permeáveis ao se redor e adequação da saída da água do Córrego.
\end{abstract}

Palavras-chave: Poluição. Degradação. Omissão. Ação Antrópica

\section{Introdução}

A Resolução do Conselho Nacional do Meio Ambiente (CONAMA) n. 001, de 23 de janeiro de 1986 define como impacto ambiental qualquer alteração das propriedades físicas, químicas e biológicas do meio ambiente, causada por qualquer forma de matéria ou energia resultante das atividades humanas que afetam o bem-estar humano.

O ser humano é o transformador do espaço nas relações sociais, afetivas e ambientais, conquista espaços sem que haja uma avaliação ambiental consistente. $\mathrm{O}$ homem altera o meio ambiente, quando escolhe um local para fixar residência, cultiva o solo, quando cria animais, ações que degradam em maior ou menor grau a natureza. São perceptíveis alterações socioambientais no meio urbano ao ser visualizado abertura de ruas, loteamentos, na falta de planejamento urbano, e ausência de previsão de 
possíveis impactos ambientais. Essa vontade de conquistar espaços culmina na destruição da natureza em prol do lucro conforme é analisado no fragmento abaixo:

Nesse sentido, prever impactos é um ato de tomada de precauções para garantir a harmonia e compatibilizar funções no interior do espaço total futuro. É também, por extensão, um ato de bom senso, em que se procura harmonizar o desenvolvimento com um correta postura de proteção ambiental e ecológica. E, evidentemente, sem abrir flanco para os apetites e expectativas ilimitadas dos gananciosos e especuladores que integram no interior diabólico do capitalismo selvagem. (AB’SABER, 1994, p. 31)

A transformação natural do crescimento atingiu o Município de Uberlândia-MG que desenvolveu-se rapidamente em razão de possuir várias empresas que contribuíram para a arrecadação de tributos, geração de empregos, bem como por possuir universidades, abundância hídrica, dentre outros atrativos. Com o crescimento do centro urbano iniciou-se as especulações imobiliárias que comercializavam vários empreendimentos sem que fossem observadas, de forma mais atenta, as questões ambientais em algumas bacias hidrográficas foram prejudicadas no que tange aos projetos de dimensionamento dos canais fluviais contribuindo para degradação dos mananciais dos córregos, desvios de cursos d’água, causando enchentes.

Ao observar a deficiente organização dos loteamentos verificou-se que passados os anos as áreas de impermeabilidade cresceram, os córregos ficaram saturados, as enchentes aumentaram nos bairros próximos aos leitos dos rios devido as falhas de escoamento das águas das chuvas mais intensas, e favelas foram sendo montadas nas áreas de preservação ambiental com ligação de esgotos domésticos clandestinos. Com todo esse cenário surgiu a necessidade de investigar as possíveis causas das inundações das ruas próximas ao Córrego Lagoinha, bem como os motivos da crescente poluição do Córrego.

Depois das análises e estudos do objeto de pesquisa surgiu o objetivo de fazer análises mais aprofundadas das recorrentes inundações do Córrego Lagoinha no período chuvoso, bem como verificar o motivo da cor escurada da água com exagero de espumas brancas e mal cheiro da água.

A importância do trabalho está no fato de que é necessário conhecer as causas das poluições clandestinas e das frequentes inundações para posteriormente serem levadas ao conhecimento do administrador público para que sejam realizadas ações eficientes de contenção das águas das chuvas para evitar novos alagamentos que invadem casas, avenidas, bem como o aumento da poluição. Para organizar os estudos elegeu-se o método dialético destacado por Spósito, (2004, p.39).

O prejuízo além de ser econômico em relação às inundações, também se pauta no contexto de o prejuízo também estar relacionado com a degradação de uns dos principais recursos hídricos urbanos do Município de Uberlândia-MG, porquanto com a crescente urbanização vários canais de esgotos 
XVII Simpósio Brasileiro

de Geografia Fisica Aplicada

I Congresso Nacional

de Geografia Física

\section{OS DESAFIOS DA GEOGRAFIA FÍSICA NA FRONTEIRA DO CONHECIMENTO \\ Instituto de Geociências - Unicamp \\ Campinas - SP \\ 28 de Junho à 02 de Julho de 2017}

clandestinos foram ligados no leito do Córrego para esgotar dejetos descartados pelos barracos construídos na área de preservação ambiental.

A área de estudo está visivelmente prejudicada com a contaminação devido aos esgotos clandestinos, mas não é só a degradação da água que está causando a degradação ambiental, pois foi verificado que o curso d'água estão sendo naturalmente desviado pela grande quantidade de restos de materiais de construção que desce com as enxurradas para o leito e com essa material está ocorrendo o prolongamento lateral causando desmoronamento dos barracos dos ribeirinhos que estão muito próximos dos barrancos que ainda estão sustentando as moradias. Há também o assoreamento que chega à rua onde já está iniciando a destruição do asfalto podendo passar para toda a extensão da rua. Na figura 1 é possível verificar o assoreamento chegando à rua. Na figura 2 está demonstrado a extensão da rua e os lotes inclinados onde não são construídas casas por receio da rua ser efetivamente destruída pelo assoreamento. As figuras 1 e 2 representa a margem direita (sentido norte/sul) do Córrego Lagoinha onde foram loteados os imóveis de alto padrão. Já as figuras 4, 5 e 6 demonstram o lado esquerdo do Córrego, porém há $1 \mathrm{Km}$ de distância das figuras 1 e 2, onde as ligações clandestinas feitas pelos moradores das favelas se aglomeraram em aproximadamente 1,5km do leito do Córrego Lagoinha. Nos dias de chuvas fortes a única saída da água é a ilustrada na figura 3, uma manilha de concreto com $80 \mathrm{~cm}$ de diâmetro que não suporta o volume de água e causa a enchente do local.

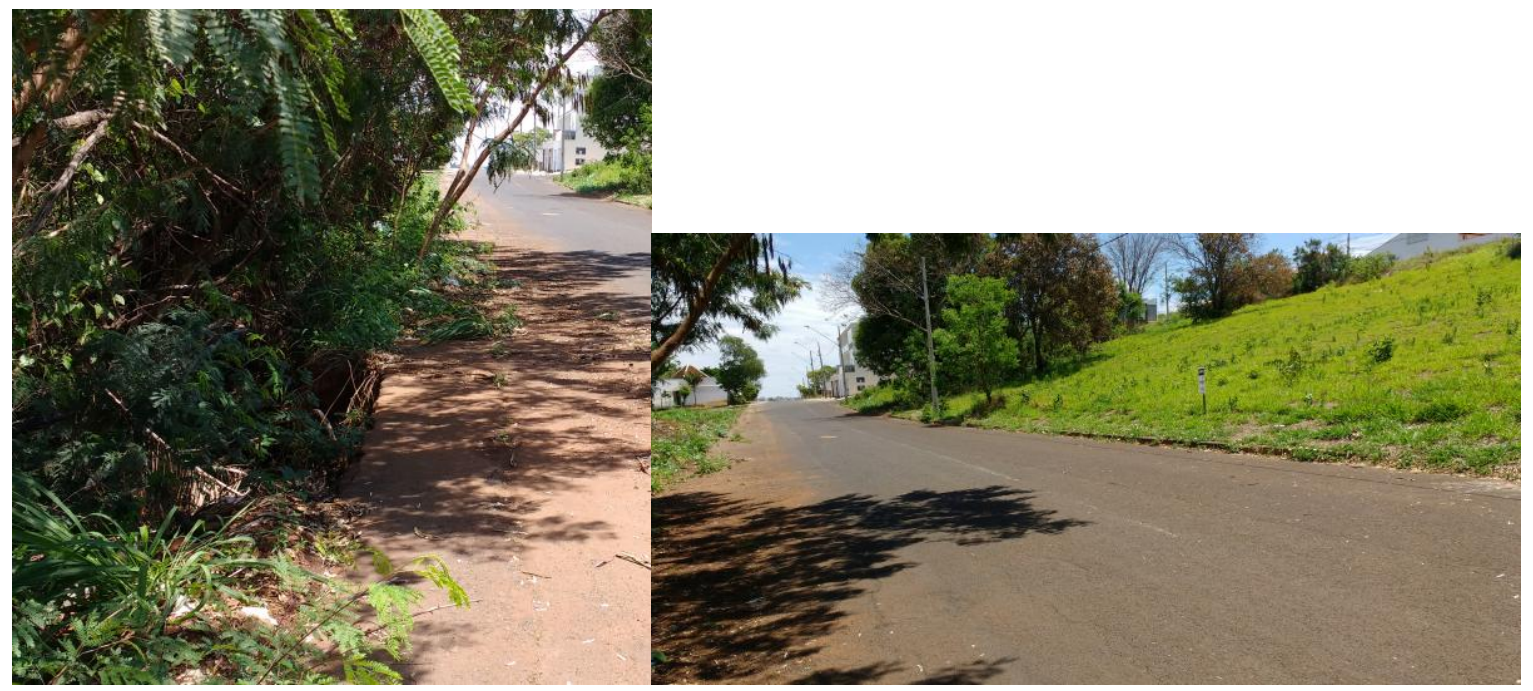

Figura 1: Assoreamento chegando à rua

Figura 2: Continuação da rua da figura 01.

Para ilustrar o trabalho e demonstrar como são as ligações clandestinas foi fotografado o local e a seguir tem três figuras que detalha a questão do esgoto clandestino. Na figura 4 está a imagem da ligação do esgoto do banheiro. Para não haver confusão nas redes os moradores ribeirinhos padronizaram o cano branco para esgoto de banheiro, conforme figura 4 e 6 . Já para o esgoto proveniente do banheiro foi padronizado o cano de cor preta, conforme destacado na figura 5. 

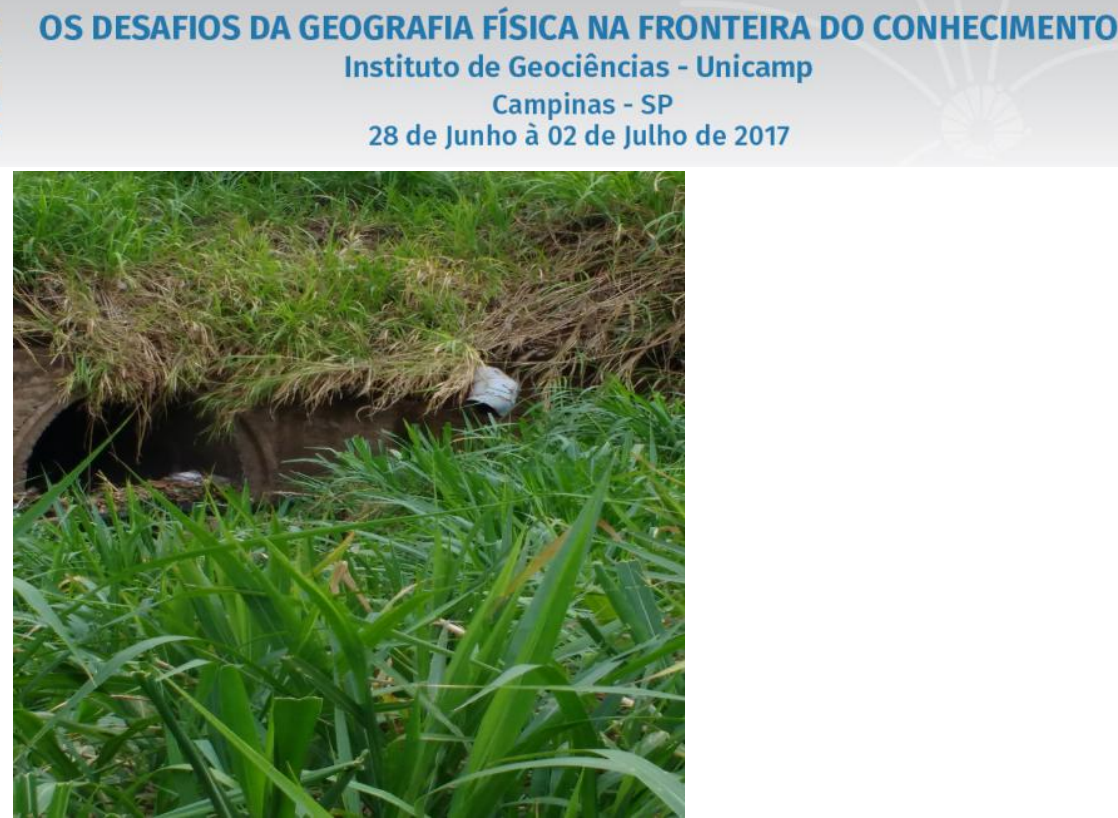

Figura 3: única manilha de vazão da água do Córrego

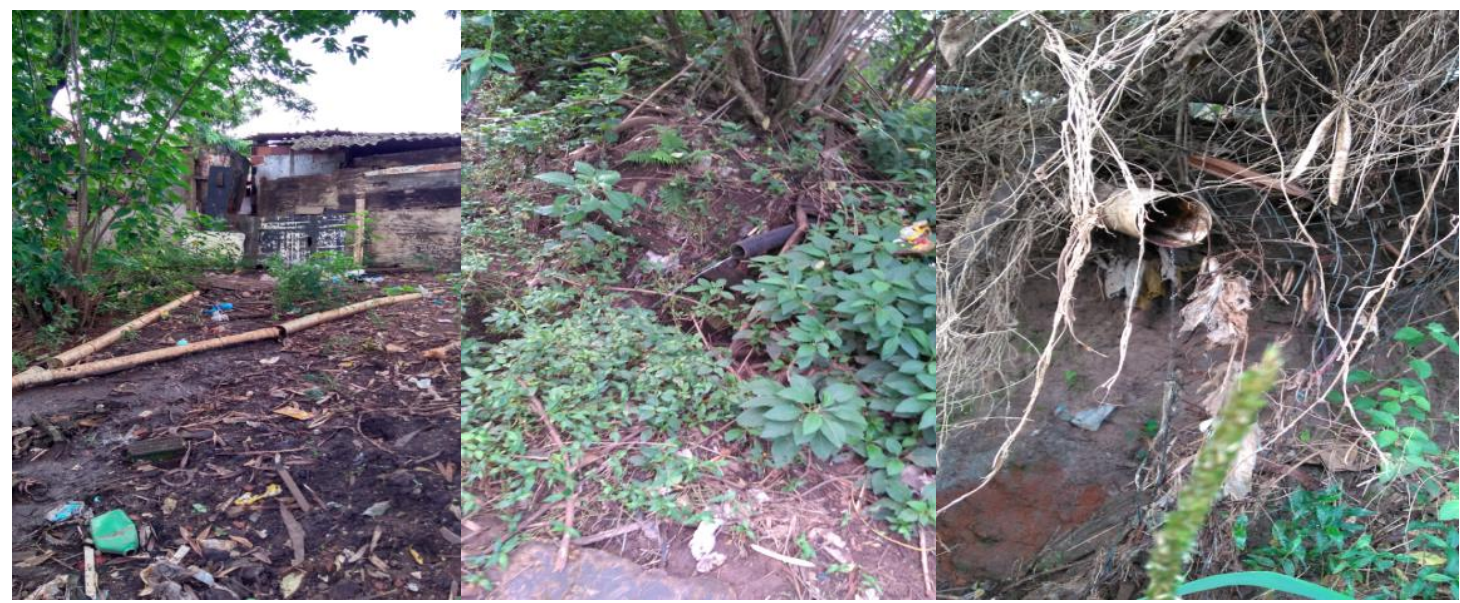

Figura 4: Ligação Banheiro
Figura 6: Esgoto de Banheiro

As figuras 4, 5 e 6 demonstram a falta de respeito que a população ribeirinha tem com o uso da água, principalmente da Bacia Hidrográfica do Córrego Lagoinha que desagua diretamente no Rio Uberabinha, que é o principal Rio que abastece o Município de Uberlândia-MG.

Essa importante Bacia Hidrográfica é de acordo com Tucci (1197, p.5-12) área de captação natural da água advinda da precipitação, a qual faz convergir os escoamentos para um único ponto de saída chamado de exutório. A figura 3 pode sim ser o exutório do Córrego, vez que ela é a única saída de todo o volume de água que a Bacia recebe e ainda é um dos causadores das enchentes por dois motivos: o primeiro pela pequena saída para o grande volume de água nos dias de chuvas intensas; a segunda por entupir com galhos de arvores e lixo ocasionando assim a passagem de água por cima da rua causando grandes transtornos no trânsito e inundação das casas vizinhas. 


\section{OS DESAFIOS DA GEOGRAFIA FÍSICA NA FRONTEIRA DO CONHECIMENTO Instituto de Geociências - Unicamp \\ Campinas - SP \\ 28 de Junho à 02 de Julho de 2017}

A água do Município além de abastecer a população ainda serve de matéria prima para as fabricas de refrigerantes e cervejaria que consomem água em volume considerável, sendo necessário, portanto que haja intervenção do poder público para regularizar tanto os esgotos clandestinos, como resolver a situação de impermeabilização do local. Entende-se que esse fenômeno de devastação hídrica esteja ligada ao conceito de expansão da suburbanização destacado por Santos (1981, p. 38).

\section{Localização e caracterização da área de pesquisa}

A pesquisa foi realizada no município de Uberlândia (MG) que está localizado no Triângulo Mineiro. Abrange uma vasta área territorial onde se localizam importantes bacias hidrográficas como: bacias Hidrográficas do Rio Tejuco e Araguari, ambos afluentes do Rio Paranaíba. De acordo com Instituto Brasileiro de Geografia e Estatística (IBGE, 2010) o município possui aproximadamente 4.115.206 km² de área, população estimada em 2015 de 664.362 habitantes.

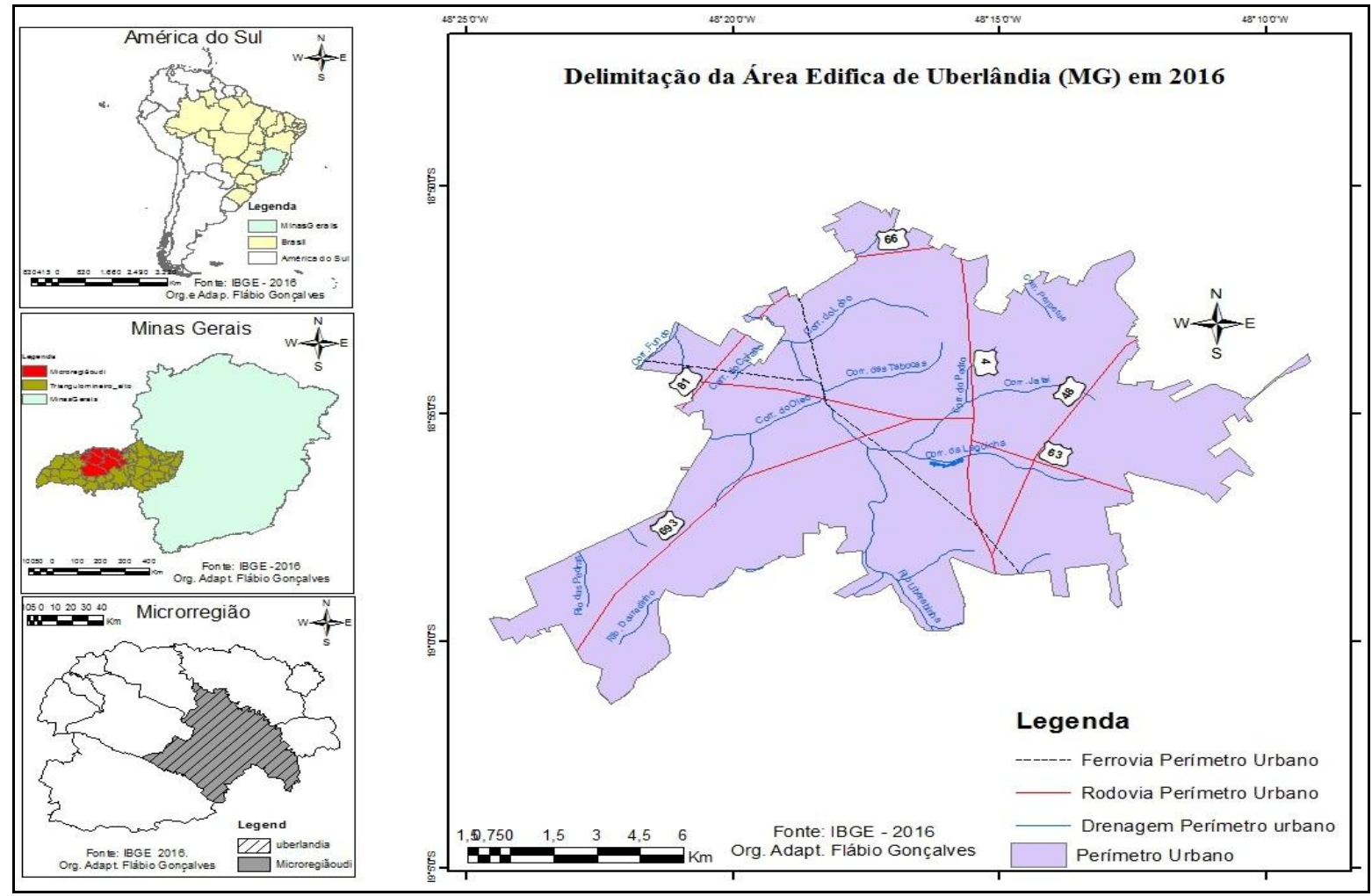

Figura 07 - Figura da localização do Município de Uberlândia, MG. Fonte: IBGE 2016

O objeto do trabalho foi a Bacia Hidrográfica do Córrego Lagoinha, que é afluente urbano do Rio Uberabinha. O Córrego está localizado na região Sudeste de Uberlândia-MG, e tem sua nascente no Córrego São Pedro, tem um afluente, o Córrego Mogi. O Córrego Lagoinha tem um trecho canalizado que é determinante para inundações por não permitir a vazão das águas das chuvas de grande volume. 
XVII Simpósio Brasileiro

de Geografia Física Aplicada

I Congresso Nacional

de Geografia Física
OS DESAFIOS DA GEOGRAFIA FÍSICA NA FRONTEIRA DO CONHECIMENTO

Instituto de Geociências - Unicamp

Campinas - SP

28 de Junho à 02 de Julho de 2017

\section{A humanidade transformou os espaços sujeitando-se ao capitalismo e à globalização.}

Um dos vilões da natureza, o lucro, tem em seu caminho um entrave chamado Geografia, pois com suas diversas transformações ao longo de sua existência trouxe para si a responsabilidade de orientar o ser humano para a ocupação regular dos espaços em que escolheu para viver, trabalhar e dessa forma a conscientização do cidadão caminha para uma melhor qualidade de vida, caminho inverso ao visado pelo capitalismo.

As questões ambientais hodiernamente estão sempre em debate. De forma bastante embrionária a educação ambiental surge na segunda metade do século XIX. É claramente verificado em UberlândiaMG que o meio ambiente ficou em segundo plano na maioria dos loteamentos urbanos, pois a dialética entre progresso e sustentabilidade ficou apenas no campo utópico, pois perdeu espaço para o capitalismo. O progresso que era a venda dos terrenos foi cumprido, no entanto, a sustentabilidade que era a preservação ambiental ficou apenas nas palavras e não se efetivou.

O capitalismo é um dos responsáveis pela degradação ambiental, debatido em diversas conferências e reuniões em favor do meio ambiente como, por exemplo, a Convenção de Estocolmo em 1972, programas da Unesco em 1975, Canadá, México, Eco-92, a Rio +20, Agenda 21, são institutos desse nível que alerta o mundo para as questões ambientais até o ano de 2020, conforme se verificou do Clube de Roma na reunião em Estocolmo (1972)[...]. (LIMA-E-SILVA, GUERRA, DUTRA, 2004, p. 181).

No caso do objeto da pesquisa foi verificado que os loteamentos foram realizados de forma lógica no discurso e desorganizada na prática, causando desequilibro social, ambiental e financeiro que atende apenas aos interesses do capital. Cabe ressaltar que, o sistema sai da aparência do dever ser para o que poderia ser, pois é nítida a contradição do discurso, vez que deveria ser preservado o meio ambiente, mas não foi, vez que há problemas com o Córrego devido à falta de planejamento ambiental consistente no início dos loteamento.

O movimento contraditório verificado na prática segundo os dizeres de Sposito (2004. p.39) destaca que ao utilizar-se da dialética "os pensadores confrontam opiniões, os pontos de vista, os diferentes aspectos do problema, as oposições e contradições"[...], no entanto, em que pese as palavras sofistas dos loteadores nada foi cumprido. A sociedade está sentindo as repercussões da degradação ambiental da bacia do Córrego Lagoinha devida ao capitalismo, às vendas de imóveis que causaram a impermeabilidade do solo e as consequentes enchentes nas ruas e no Córrego.

Há um hiato do discurso entre progresso e sustentabilidade e é nitidamente percebido nas ações dos capitalistas e nas possíveis omissões do poder público local que prometem loteamentos que vão preservar o meio ambiente e depois das vendas a promessa parece cair em esquecimento e a degradação ambiental é inevitável frente ao capitalismo que clama por progressos, por metas, recordes 
XVII Simpósio Brasileiro

de Geografia Física Aplicada

I Congresso Nacional

de Geografia Física
OS DESAFIOS DA GEOGRAFIA FÍSICA NA FRONTEIRA DO CONHECIMENTO

Instituto de Geociências - Unicamp

Campinas - SP

28 de Junho à 02 de Julho de 2017

e mais recordes; no entanto, por outro lado, o meio ambiente demonstra consequências em virtude da baixa sustentabilidade.

A humanidade necessita de espaço para sobrevivência, abrigo, relações sociais e para tanto vem modificando os espaços naturais à sua necessidade e nem sempre de forma planejada conforme é visto na sociedade contemporânea com favelas desorganizadas, ruas com enchente, alagamentos. A sociedade capitalista com vistas à globalização é uma das grandes destruidoras da natureza rompendo sistematicamente com a tríade homem/sociedade/natureza.

Para Porto-Gonçalves (2006, p. 18), o processo de globalização traz a exploração da natureza com proveitos e rejeitos distribuídos desigualmente. Esse modo globalizado e de produção capitalista desenvolveu no ser humano a forma de sujeito e na natureza a forma de objeto onde o ser humano se apropriou da natureza através do trabalho, pois a natureza é explorada com visão de lucro e o setor econômico com maior possibilidade de extração da natureza vai poder conseguir mais privilégios que os trabalhadores que apenas usam de sua força de trabalho para manter o ciclo do capitalismo que concentra a riqueza nas mãos de poucos e não distribui o lucro de forma igualitária. Nesse sentido, é a desigualdade proveniente da exploração da natureza.

Em suma, está claramente demonstrado a contradição do discurso, pois não há desenvolvimento sustentável quando o objetivo final do capitalista é apenas o lucro com a venda dos terrenos, pois se o discurso do desenvolvimento sustentável fosse realmente aplicado haveria cumprimento do plano de conservação ambiental, assim como precaução com as Áreas de Preservação Ambiental (APP) as quais não tiveram a devida atenção e, atualmente, estão se transformando em passeios concretados o que vai gerar mais danos ambientais para a área em estudo.

O trabalho trouxe a discussão da impermeabilização das áreas próximas do Córrego como uma das causas de sua inundação em dias de chuvas de grande volume. No decorrer das pesquisas foi implantado o parque linear às margens do Córrego o que dá a sensação de que o Córrego está sendo protegido pelo poder público, no entanto, apenas um parque linear que é um passeio de concreto para caminhadas não demonstra que está sendo revitalizada água do manancial hídrico.

\section{Consolidação da Geografia como Ciência e contribuição para o estudo ambiental}

A discussão em torno da Geografia como ciência foi bastante agitado, no entanto, antes de adentrar ao historicismo da ciência é necessário iniciar esse tópico com destaque a função pedagógica da Geografia no caminhar da história, pois ela permite que haja formação crítica do cidadão frente aos acontecimentos do mundo em que vive tornando-o pessoa que seja capaz de compreender o seu meio e o mundo globalizado. A Geografia como ciência permite que se possa criar condições para que o 
OS DESAFIOS DA GEOGRAFIA FÍSICA NA FRONTEIRA DO CONHECIMENTO Instituto de Geociências - Unicamp Campinas - SP

28 de Junho à 02 de Julho de 2017

objeto de pesquisa passe por reestruturação ambiental e possa definitivamente ser um córrego isento de poluição, basta que o poder público se utilize das ferramentas da geografia de despoluição e tratamento da água para que se possa realmente conseguir dar uma nova vida à Bacia Hidrográfica, pois o resultado encontrado no local foi de situação de abandono, mal cuidado e com a água com coloração que facilmente é percebido pelo cidadão comum que trata-se de água contaminada.

A Geografia tem fundamental importância no ensino, pois de acordo com Capel (2010, p. 30) que destaca que a tarefa principal que a geografia universitária tratou de desenvolver foi a formação de professores para o ensino primário e secundário; por meio deles, pensava-se elevar a qualidade dos conhecimentos geográficos ao país. Veja que assiste razão ao Capel, pois é por meio do estudo da Geografia que o ser humano toma contato com diversas formas de pensar criticamente o meio em que vive, e também conhecer e compreender a importância da preservação ambiental do meio em que habita. É importante destacar que antes de tornar-se uma ciência de ensino secundário houve diversas correntes referentes a geografia.

A geografia assim como as outras ciências não tem definição exata, pois cada estudioso tem sua noção do que é a ciência que estuda. Andrade (1987, p.11) destaca que existe admissão de que a Geografia se tornou uma ciência autônoma desde o século XIX com o trabalho dos autores Alexandre Von Humbold e Karl Ritter na Alemanha. Andrade (1987, p.11) destaca ainda que a Geografia na préhistória era limitada a descrição de roteiros, indicar recurso e analisar as relações meteorológicas o que levou a ciência a ser intimamente ligada à Cartografia e à Astronomia. Pode-se destacar que nessas viagens foi possível descrever paisagens e as formações da natureza em todos os locais, natureza essa pouco degradada devido à falta da ação humana, situação totalmente contrária do objeto dessa pesquisa que depois de aberturas de ruas e construção de imóveis houve a degradação da área do Córrego.

Em continuidade aos caminhos da Geografia, Andrade (1987, p. 11) relata que na idade contemporânea as questões geopolíticas estavam intimamente ligadas com os estudos da geografia como disciplina autônoma, pois Ritter, filosofo e Historiador, aprofundou seus estudos na área da geografia física que estava em rota de colisão com a visão de Humboldt que por ter pensado a geografia através de várias análises teve a visão da geografia como naturalista, conceito esse extraído das várias viagens que realizou em buscas de respostas do ponto de vista geográfico, possivelmente procurando modelos para uma sociedade mais consciente ambientalmente .

\section{Desenvolvimento da pesquisa}


XVII Simpósio Brasileiro

de Geografia Fisica Aplicada

I Congresso Nacional

de Geografia Física
OS DESAFIOS DA GEOGRAFIA FÍSICA NA FRONTEIRA DO CONHECIMENTO

Instituto de Geociências - Unicamp

Campinas - SP

28 de Junho à 02 de Julho de 2017

A metodologia de pesquisa que é a elaboração do saber científico partiu-se da escolha do tema, caminhou-se pela realização dos planejamentos, metodologias e observação do método o que permitiu o levantamento de dados preliminares.

A pesquisa tem por objetivo buscar respostas e para tanto deve ser embasada por planejamento e execução que partem de um processo sistematizado que compreende várias etapas que inicia na escolha do tema e chega a discussão dos resultados. Essa pesquisa partiu da preocupação com a degradação ambiental que aumenta a cada ano no leito da Bacia Hidrográfica do Córrego Lagoinha.

Para formatar o trabalho foram verificadas no local todas as informações empíricas para que a pesquisa fosse desenvolvida e posteriormente fosse verificado que o método utilizado respondeu bem todas as problemáticas apresentadas que era a verificação dos motivos de poluição enérgica do Córrego, bem como a alta concentração de água nos dias de chuvas torrenciais. As enchentes são causadas pelo vasto terreno impermeável, a degradação devido aos esgotos clandestinos e o assoreamento devido à falta de vegetação natural do local que está praticamente eliminada do local.

As análises preliminares foram importantes para pensar um modelo para diminuir a degradação ambiental, pois houve análise quantitativa que possibilitou responder às indagações referentes às enchentes e à degradação dos recursos naturais. O trabalho de campo teve importância impar conforme destaca Godoy (1995, p.62), pois toda a pesquisa foi realizada no local com a observação de todas as vegetações, solo e degradação do local. Essa avaliação do local possibilitou a equacionar todas as indagações acerca do tema e a responder as questões que permeia o trabalho, qual seja: a origem das enchentes que são a falta de impermeabilização do local e excesso de lançamento de esgotos direito no curso d’água.

Para o estudo, análise dos dados e conclusão do trabalho foram utilizados os seguintes métodos: observação, descrição, coleta de dados, mapas e tabelas. As bases de orientação dos trabalhos foram: 1. Pesquisa teoria; 2. Pesquisa de documentos; 3. Pesquisa de campo. A pesquisa teórica partiu de leituras de trabalhos já realizados na área como: dissertações, artigos científicos, leis, resoluções, portarias, pesquisa via rede mundial de computadores, revistas e autores como: Melo (2012), Pinto (2005), Silva (2004).

As pesquisas de campo foram contemporâneas às leituras uma vez que é de suma importância para o desenvolvimento do artigo, pois consiste na observação que inteirou o sujeito e o objeto, vez que o campo como realidade não é separado do sujeito e por esse motivo os trabalhos foram de observação com análises de campo e dados em dissertações dos arquivos da Universidade Federal de Uberlândia.

No campo foi observado que realmente o Córrego Lagoinha está com odor com características de esgoto doméstico, assoreamento em diversas partes. Em relação às enchentes essas foram observadas 
no dias de chuvas de grande volume, vez que as ruas asfaltadas, aliado aos concretos dos passeios dos imóveis e à única forma de vazão da água apresentada na figura 3, o Córrego enche as margens invadindo as ruas laterais, os barracos das favelas e por vezes as casas até setenta metros de distância do leito do Córrego.

A pesquisa teve como resultado a confirmação de que não há vazão suficiente da água do Córrego para chegar ao Rio Uberabinha em temporada de chuvas intensas e por esse motivo causam as inundações. Em trabalhos empíricos foi verificado que a única saída da vazão da água, figura 3, o excesso de lixo no leito do Córrego, as áreas impermeáveis como: ruas asfaltadas, passeios de concretos, casas com quintais cimentados, são fatores que colaboram para impermeabilização do solo e as consequentes inundações das vias. Assim, a urbanização rápida às margens dos Córregos ou rios conduz a alterações significativas nas formas, conforme é explicado abaixo:

Com a urbanização, verifica-se que alterações na rede de drenagem natural, que é substituída por estruturas artificiais, aumentos na rede de drenagem natural, que é substituída por estruturas artificiais, aumento na extensão de áreas impermeáveis e mudanças de microclima local. Tais alterações provocam maior volume de água pluvial escoada mais rapidamente, gerando segundo dos maiores problemas hidrológicos: o controle de enchentes". (TUCCI E MARQUES, 2000. p. 25)

Tucci e Marques destacam que para tentar solucionar os problemas devem existir bases confiáveis para possibilitar uma visualização correta do cenário de impacto e verificar ainda buscas das causas e estudos sobre as situações futuras. No que concerne ao objeto de estudo é perceptível que a impermeabilidade do local aliada às estruturas artificiais, estão modificando a forma de escoação natural do Córrego e causando todos os problemas estruturais.

Pelas pesquisas do local percebe-se que os estudos da área que devem ser constantes, segundo Pacheco (1998, p. 16), existe a necessidade de atualização dos registros de uso da terra, para que suas tendências possam ser analisadas, e pelo que foi percebido essa atualização não foi realizada nas proximidades do Córrego e nem mesmo avaliada a declividade do local que possibilita grande volume de água de chuvas desaguar no seu canal.

Para Câmara e Devis (2002) o estudo das interações da declividade podem ser feitos através de geoprocessamento permitindo a identificação de áreas propicias à degradação ambiental e avaliação das estratégias de manejo antes mesmo delas serem adotadas; essa identificação é importante, pois a bacia hidrográfica independente de sua dimensão possui importância fundamental na área urbana da cidade. Para Pinto (1976, p.38) "bacia hidrográfica é a área geográfica coletora de água de chuva que, escoando pela superfície atinge a seção considerada". Assim, a organização de geoprocessamento seria o ideal para que evitasse o grande volume de água que atinge o Córrego em dias de chuvas intensas. 


\section{Considerações finais}

Os documentos pesquisados no curso de Geografia da Universidade Federal de Uberlândia (UFU), como: dados, mapas, imagens revistas referente ao local da pesquisa permitiu perceber como foi rápido o movimento de impermeabilização ao redor do Córrego Lagoinha com a crescente urbanização no local nos últimos trinta anos.

A partir das visitas no local foi visto que a erosão que assenta uma ampla quantidade de terra é levada pelas águas ao longo de todo o córrego, e se formam alguns bolsões. Também foi avaliado que há partes do córrego que está quase no nível da rua devido ao assoreamento.

No que tange à degradação ambiental vista no Córrego Lagoinha, aliado ao tema do artigo é importante que haja uma modelagem no sistema de escoamento de água nas vias urbanas ao redor do Córrego Lagoinha, onde tenha ruas com sistema de captação de água que seja eficiente, assim como tanques de grande volume para armazenamento da água da chuva para evitar que essa água pluvial chegue com alto volume nas ruas e avenidas da área urbana. Com os tanques de retenção da água das chuvas fortes é possível que seja uma solução para o problema que afeta Uberlândia-MG há muitos anos.

As análises permitiram verificar que o processo de degradação do Córrego Lagoinha está avançado e a causa está relacionada com a falta de cumprimento da legislação referente ao planejamento urbano e às normas ambientais, inobservância das regras de infraestrutura, visto que o esgoto doméstico está sendo jogado diretamente no Córrego, o que também contribui para deterioração da Bacia.

É a partir do conhecimento que é possível construir e superar as formas de expropriação que possibilita a dicotomia sociedade-natureza. Com isso, a crise socioambiental será superada com os esforços governamentais e não governamentais. A união homem/natureza possibilitará a diminuição da degradação ambiental para as futuras gerações um meio ambiente sadio. A construção do pensamento geográfico, social e natural é latente, dinâmico e está em profundas transformações diariamente o que se deve alinhar à história e continuar caminhando atento sempre as transformações sociais.

A solução para o problema já está idealizada, no entanto, para que seja apresentada de fato ao público é necessária, primeiramente, a comprovação efetiva com dimensionadores matemáticos como, por exemplo, simuladores de chuvas e cálculos da velocidade da água, para que não seja apresentado trabalho baseado só em hipóteses e sim em pesquisa empírica.

Em suma, observa-se que a geografia é de fundamental importância nos estudos de espaços geográficos, na relação sociedade/natureza, nas discussões socioambientais onde o processo educativo ambiental tem um papel importante para o progresso sustentável e a redução da degradação ambiental. 


\section{Bibliografia}

AB'SABER. A. N.. Bases Conceptuais e papel do conhecimento na previsão de impactos. In: AB'SÁBER, A. N.; MÜLLER-PLANTENBERG, C. (Orgs.). Previsão de impactos: o estudo de impacto ambiental no leste, oeste e sul: experiências no Brasil, na Rússia e na Alemanha. São Paulo: EDUSP, 1994.

ANDRADE, M. C. de. Ciência da sociedade: uma introdução à análise do pensamento geográfico. São Paulo: Atlas, 1987. p.11.

BRASIL. Constituição (1988). Constituição da República Federativa do Brasil. 24. ed. Rio de Janeiro: Edipro, 2015.

BRASIL. CONAMA. Conselho Nacional do Meio Ambiente. Resolução CONAMA No 001, de 23 de janeiro de 1986. Brasília, Distrito Federal. Disponível em: Acesso em: 04 nov. de 2016.

CÂMARA, G.; DAVIS, C. Apresentação. In: CÂMARA, G; DAVIS, C.; MONTEIRO, A. M.V. Introdução à Ciência da Geoinformação. 2002. cap. 1. Disponível em: <http://www.dpi.inpe.br/gilberto/livro/introd/>. Acesso em: 14/04/2017.

CAPEL, H. Geografia contemporânea: ciência e filosofia. Tradução de Jorge Ulisses Guerra Villalobos. Maringá: Eduem, 2010.

GODOY, A. S.. Introdução à pesquisa qualitativa a e suas possibilidades. Revista de Administração de Empresas, São Paulo, v. 35, n. 2, p. 57-63, mar./abr. 1995. p.62.

GOMES, P. C. da C. Geografia e modernidade. Rio de Janeiro: Bertrand Brasil, 1996.

IBGE. Instituto Brasileiro de Geografia e Estatística. Dados sobre as cidades. Disponível em: <www.ibge.com.br>. Acesso em: 05 nov. 2016.

LIMA-E-SILVA, P. P.; GUERRA, A. J. T.; DUTRA, L..E. D.. Subsídios para avaliação econômica de impactos ambientais. In: CUNHA, S.B.; GUERRA, A.J.T. (org.) Avaliação e perícia ambiental. 5. Ed., Rio de Janeiro: Bertrand Brasil, 2004. p. 217-257.

MELO, M. C. A. A interação homem-natureza na bacia hidrográfica do Córrego Bebedouro no município de Uberlândia (MG). Catalão: UFG, 2012. 112f. Dissertação (Mestrado em Geografia) - Programa de PósGraduação em Geografia da Universidade Federal de Goiás, Campus Catação (GO), 2012.

PACHECO, A. P., RIBAS, N. S., Sensoriamento Remoto aplicado ao Uso da Terra. GEODÉSIA online. Revista da Comissão Brasileira de Geodésia. Recife, v. 4, 1998.

PINTO, N. L. de S. et al. Hidrologia Básica. São Paulo: Editora Edgard Blucher, 1976. p.38.

PORTO-GONÇALVES. C. V.. A globalização da natureza e a natureza da globalização. Rio de Janeiro: Civilização Brasileira, 2006. p. 18.

SANTOS, M. Manual de Geografia Urbana. Coleção Geografia: Teoria a Realidade. São Paulo. Editora Hucitec, 1981. p. 38.

SILVA, J. F.; RODRIGUES, S. C. Síntese ambiental e evolução do uso e ocupação do solo da bacia hidrográfica do Córrego do Salto, Uberlândia (MG). Uberlândia. Revista Caminhos da Geografia. V. 6, n. 12, Jun 2004, p. 114-127. Disponível em: www.ig.ufu.br. Acesso em: 01 nov. 2016.

SPOSITO, E. S. Geografia e filosofia: contribuição para o ensino do pensamento geográfico. São Paulo: Editora da UNESP, 2004. p.39.

TUCCI, C. E. M. Plano Diretor de Drenagem Urbana: Princípios e Concepção. Revista Brasileira de Recursos Hídricos, v. 2, n. 2, p. 5-12, jul./dez.1997. 